IJEEM: Indonesian Journal of Environmental Education and Management

e-ISSN: 2549-5798

Vol.6 No. 1 Januari 2021

DOI : doi.org/10.21009/IJEEM.061.03

\title{
VALUASI EKONOMI DESTINASI PULAU HARAPAN, TAMAN NASIONAL KEPULAUAN SERIBU DKI JAKARTA
}

\author{
Yusuf Ilyasa Ilham ${ }^{1}$, Mahawan Karuniasa ${ }^{2}$, Yuki M.A Wardhana ${ }^{3}$ \\ ${ }^{I}$ Mahasiswa Sekolah Ilmu Lingkungan Universitas Indonesi \\ ${ }^{2}$ Pengajar Sekolah Ilmu Lingkungan Universitas Indonesi ${ }^{2}$ \\ ${ }^{3}$ Pengajar Sekolah Ilmu Lingkungan Universitas Indonesia
}

\begin{abstract}
ABSTRAK
Sektor pariwisata adalah salah satu sektor yang sangat potensial untuk meningkatkan devisa negara. Indonesia memiliki banyak destinasi pariwisata alam. Salah satu destinasi pariwisata alam di Indonesia adalah Taman Nasional Kepulauan Seribu. Pada tahun 2018, pemerintah menetapkan Kepulauan Seribu sebagai Kawasan Strategis Pariwisata Nasional (KSPN). Pemerintah menetapkan target penerimaan negara bukan pajak (PNBP) dari Kepulauan Seribu sebesar Rp.150.000.000. Target tersebut harus dicapai dengan proses yang memberikan dampak sekecil mungkin terhadap lingkungan. Salah satu alternatifnya adalah dengan membuat wisata eksklusif. Penelitian ini mengkaji destinasi wisata Pulau Harapan untuk menentukan nilai ekonomi dari destinasi wisata Pulau Harapan dan menyesuaikannya dengan target PNBP dan daya dukung. Metode yang dipakai pada penelitian ini adalah mencari nilai ekonomi menggunakan metode Contingent Valuation Method (CVM) dan mencari Break Even Point (BEP) dan daya dukung optimum di destinasi wisata P.Harapan. Hasil dari penelitian ini, destinasi wisata P.Harapan dapat dijual dengan harga Rp.727.500 dengan jumlah wisatawan yang terbatas yaitu sebanyak 4337 wisatawan.
\end{abstract}

Kata kunci: Valuasi Ekonomi, Pariwisata, Willingness To Pay, Ability To Pay 


\section{PENDAHULUAN}

Sumber pendapatan suatu negara dapat diperoleh melalui sektor pariwisata. Panjangnya rantai pariwisata (Tourism Supply Chain) membuat banyak sektor berperan di dalamnya seperti sektor transportasi, infrastruktur, makanan dan minuman, dan masih banyak lagi. Pemerintah Indonesia terus membangun infrastruktur untuk menciptakan kontektivitas yang tinggi antar lokasi untuk mendukung kegiatan pariwisata. Pemerintah juga terus memperbaiki sarana dan prasarana pintu masuk wisatawan mancanegara dan wisatawan domestik seperti pelabuhan, bandara, stasiun, dan jalan bebas hambatan.

Indonesia adalah salah satu negara yang menjadi tujuan pariwisata dunia. Sumber daya alam dan keanekaragaman hayati yang tinggi membuat Indonesia selalu ramai untuk menjadi destinasi pariwisata. Akan tetapi, tujuan wisata tersebut belum menyeluruh dan hanya tertuju kepada beberapa titik destinasi saja seperti Bali, Raja Ampat, dan juga Pulau Komodo. Oleh karena itu, untuk memaksimalkan potensi destinasi wisata di Indonesia, Pemerintah melalui PP No. 5 Tahu 2011, membuat 10 destinasi wisata prioritas atau disebut dengan "The New Bali". Sepuluh destinasi prioritas tersebut terdiri dari Danau Toba, Tanjung Kelayang, Mandalika, Morotai, Wakatobi, Tanjung Lesung, Candi Borobudur, Bromo Tengger Semeru, Labuan Bajo dan Kepulauan Seribu.

Tujuh dari sepuluh destinasi priotias tersebut adalah destinasi wisata bahari. Indonesia sebagai negara kepulauan memiliki potensi yang sangat tinggi untuk dijadikan sebagai destinasi wisata bahari dunia Salah satu lokasi yang menjadi destinasi prioritas adalah Kepulauan Seribu. Keunggulan dari Kepulauan Seribu adalah lokasi nya yang berdekatan dengan DKI Jakarta. Akses yang mudah dan waktu tempuh yang singkat membuat Kepulauan Seribu banyak di minati wisatawan domestik dan mancanegara. 
IJEEM: Indonesian Journal of Environmental Education and Management

e-ISSN: 2549-5798

Vol.6 No. 1 Januari 2021

DOI : doi.org/10.21009/IJEEM.061.03

Pemerintah membuat target sebanyak 20 juta wisatawan mancanegara untuk datang ke Indonesia. Berbagai cara dilakukan oleh pemerintah pusat dan daerah untuk mencapai target tersebut. Berbagai pembangunan terjadi di setiap destinasi wisata. Pembangunan tersebut memberikan dampak yang tidak sedikit terhadap lingkungan di lokasi wisata seperti adanya perubahan visual terhadap kondisi pulau di Taman Nasional Kepulauan Seribu (TNKpS). Perubahan tersebut disebabkan oleh adanya penumpukan sampah dan perubahan kualitas air yang berakibat terhadap biota perairan di TNKpS khususnya terumbu karang (Krishnamurti, 2015). Aktivitas wisatawan di TNKpS juga mengakibatkan rusaknya biota laut di perairan TNKpS. Perubahan kondisi lingkungan tersebut dapat mempengaruhi rusaknya objek daya tarik utama di TNKpS dan menurunkan nilai atraksi wisata yang ada di lokasi tersebut.

Pengembangan amenitas yang melebihi daya dukung terjadi pada sentra-sentra ekonomi dengan penduduk padat dan wilayah strategis. Saat ini terdapat 661 homestay di lokasi pemukiman dan 7 resort dengan 313 kamar di Pulau Resort (Kementerian Pariwisata, 2018). Sebagai contoh pulau yang terkena dampak adalah Pulau Air Besar, Pulau Bidadari, dan Pulau Laki, telah mengalami eksploitasi secara berlebihan sehingga merusak ekosistem terumbu karang disekitarnya (Hutomo, 1995 dalam Mujiyani et al, 2002). Penelitian Yusnita (2014) menyebutkan bahwa sekitar 19-49 \% tutupan karang di sekitar Pulau Panggang masuk dalam kategori buruk hingga sedang dengan kegiatan wisata bahari sebagai penyebab utamanya.

Pengelolaan wisata di Taman Nasional Kepulauan Seribu harus dikelola secara berkelanjutan. Pembatasan pengunjung perlu dilakukan agar jumlah wisatawan yang datang tidak melampau daya dukung di Kepulauan Seriu. Akan tetapi, dengan jumlah wisatawan yang lebih sedikit, pendapatan negara akan berkurang jika nilai retribusi tetap seperti sekarang. Nilai retribusi Pulau Seribu adalah Rp.7.000 dengan harga paket wisata sebesar Rp.300.000. Selain pendapatan negara, pendapatan masyarakat tentu akan berkurang jika jumlah pengunjung diabatasi sesuai dengan daya dukung masing- 
IJEEM: Indonesian Journal of Environmental Education and Management

e-ISSN: 2549-5798

Vol.6 No. 1 Januari 2021

DOI : doi.org/10.21009/IJEEM.061.03

masing pulau. Oleh karena itu, diperlukan nilai valuasi ekonomi yang meliputi Willingness to Pay (WTP) dan Ability To Pay (ATP) pengunjung jika destinasi wisata Kepulauan Seribu dikelola dengan prinsip ekowisata, yaitu dengan dilakukan pembatasan pengunjung dengan harapan akan meningkatkan keindahan dan keunikan Kepulauan Seribu.

Pencapaian menuju target tersebut harus dilakukan dengan perencanaan yang tepat dan pengelolaan secara berkelanjutan. Salah satu langkah untuk mencapai target tersebut adalah dengan melakukan pemasaran destinasi pariwisata agar tidak hanya jumlah wisatawan yang datang mencapai target, tetapi juga dapat meningkatkan kesejahteraan masyarakat lokal dan melindungi ekosistem yang menjadi daya tarik wisata. Usaha untuk memasarkan sebuah destinasi pariwisata dapat dilakukan dengan pengembangan produk pariwisata yang ditawarkan, penentuan harga, tempat, dan promosi destinasi pariwisata secara berkelanjutan.

\section{METODE PENELITIAN}

Metode yang dipakai dalam riset ini adalah daya dukung wisata (Yulianda, 2007). Daya dukung suatu kawasan dapat diukur dengan tingkat kepuasan wisatawan yang tertinggi dan berdampak minimal pada sumberdaya (Lim, 1998; Yulianda, 2007). Pengukuran daya dukung terbagi menjadi beberapa jenis yang dipengaruhi oleh tujuan penulis untuk mengukur objek daya dukung tersebut. Daya dukung terbagi atas daya dukung fisik, daya dukung ekonomi, daya dukung sosial, daya dukung persepsi, daya dukung ekologi, dan daya dukung politik (Getz, 1983; Kenell, 2015). Pengukuran daya dukung pada riset ini dibatasi dengan daya dukung kawasan pariwisata.

Metode analisis yang digunakan adalah membandingkan jumlah area wisata dengan jumlah maksimum wisatawan yang mengunjungi kawasan dalam satu periode tertentu 
(Yulianda, 2007). Penghitungan daya dukung kawasan dihitung dengan rumus sebagai berikut:

$$
\mathrm{DDK}=\mathrm{K} \times \underset{\mathrm{LT}}{\mathrm{Lp}} \times \frac{\mathrm{Wt}}{\mathrm{Wp}}
$$

\section{Keterangan:}

DDK = Daya Dukung Kawasan

$\mathrm{K}=$ Potensi ekologis area per satuan unit area

$\mathrm{Lp}=\mathrm{Luas}$ dan panjang area yang dapat dimanfaatkan

$\mathrm{Lt}=\mathrm{Unit}$ area untuk kategori tertentu

$\mathrm{Wt}=$ Waktu yang disediakan kawasan untuk berwisata dalam satu hari

$\mathrm{Wp}=$ Waktu yang dihabiskan wisatawan dalam kegiatan tertentu

Pengukuran daya dukung kawasan di destinasi wisata Pulau Harapan dilakukan pada empat lokasi penelitian yang terdiri dari lokasi wisata pantai. Pengukuran daya dukung kawasan diperlukan untuk mengetahui batasan maksimum pengunjung yang dapat ditampung di lokasi wisata agar tetap lestari (Katalinga, 2013). Aktivitas wisata pantai di destinasi wisata Pulau Harapan yaitu Pulau Kayu Angin Melintang, Pulau Perak, Pulau Putri, dan Pulau Gosong.

Potensi ekologis pengunjung adalah koefisien jumlah maksimum wisatawan yang dapat diterima dalam suatu satuan unit area. Waktu yang disediakan kawasan untuk berwisata adalah waktu yang disediakan pengelola dan operator wisata untuk wisatawan. Luas suatu area yang digunakan untuk kegiatan wisata harus mempertimbangkan kemampuan alam untuk memberikan toleransi terhadap jumlah pengunjung agar sumberdaya tetap terjaga (Ketjulan, 2010). Waktu kegiatan pengunjung (Wp) dihitung berdasarkan lamanya waktu yang dihabiskan oleh 


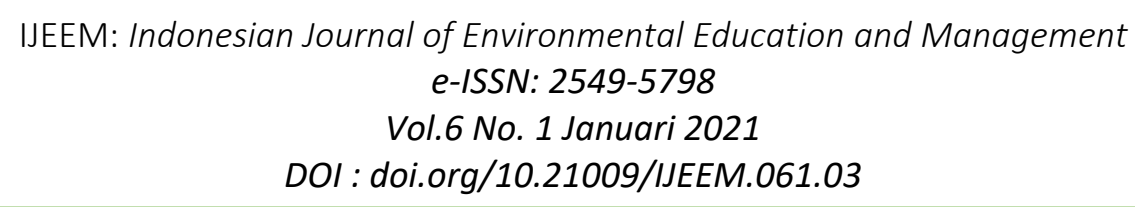

pengunjung untuk melakukan kegiatan wisata. Waktu pengunjung diperhitungkan dengan waktu yang disediakan untuk kawasan (Wt). Waktu kawasan adalah lama waktu areal untuk satu hari dan rata-rata waktu kerja. Pengelola destinasi wisata Pulau Harapan membuka area pulau efektif hanya 120 menit (2 jam) yaitu pukul 15.00-17.00 dan waktu yang dibutuhkan wisatawan untuk berwisata adalah selama 60 menit (1 jam).

Tabel 1. Keterangan Potensi Daya Dukung Kawasan

\begin{tabular}{|c|c|c|c|c|}
\hline No & $\begin{array}{c}\text { Jenis } \\
\text { Kegiatan }\end{array}$ & $\begin{array}{c}\text { Jumlah } \\
\text { pengunjung } \\
\text { (K) }\end{array}$ & $\begin{array}{l}\text { Unit area } \\
\quad(\mathbf{L t})\end{array}$ & Keterangan \\
\hline 1 & Selam & 2 & $2000 \mathrm{~m}^{2}$ & $\begin{array}{l}\text { Setiap } 2 \text { orang dalam } 200 \\
\mathrm{~m} \times 10 \mathrm{~m}\end{array}$ \\
\hline 2 & Snorkling & 1 & $500 \mathrm{~m}^{2}$ & $\begin{array}{l}\text { Setiap } 1 \text { orang dalam } 100 \\
\mathrm{~m} \times 5 \mathrm{~m}\end{array}$ \\
\hline 3 & Wisata lamun & 1 & $500 \mathrm{~m}^{2}$ & $\begin{array}{l}\text { Setiap } 1 \text { orang dalam } 100 \\
\mathrm{~m} \times 5 \mathrm{~m}\end{array}$ \\
\hline 4 & $\begin{array}{c}\text { Wisata } \\
\text { mangrove }\end{array}$ & 1 & $50 \mathrm{~m}$ & 1 orang sepanjang $50 \mathrm{~m}$ \\
\hline 5 & $\begin{array}{c}\text { Rekreasi } \\
\text { pantai }\end{array}$ & 1 & $50 \mathrm{~m}$ & $\begin{array}{l}1 \text { orang sepanjang } 50 \mathrm{~m} \\
\text { panjang pantai }\end{array}$ \\
\hline 6 & $\begin{array}{l}\text { Wisata } \\
\text { olahraga }\end{array}$ & 1 & $50 \mathrm{~m}$ & $\begin{array}{l}1 \text { orang setiap } 50 \mathrm{~m} \\
\text { panjang pantai }\end{array}$ \\
\hline
\end{tabular}

Contingent Valuation Method (CVM) untuk menentukan nilai ekonomi destinasi wisata Pulau Harapan. Metode ini digunakan untuk menanyakan kepada wisatawan tentang nilai atau harga yang mereka berikan terhadap komoditi yang tidak memiliki pasar seperti barang lingkungan (Merryna, 2009 dalam Yakin, 1997). CVM menggunakan pendekatan secara langsung yang menanyakan kepada wisatawan berapa besarnya Willingness To Pay (WTP) untuk membayar kompensasi melindungi kawasan wisata TNKpS dan Ability To Pay (ATP) untuk menilai kemampuan wisatawan membayar kompensasi tersebut. 
IJEEM: Indonesian Journal of Environmental Education and Management

e-ISSN: 2549-5798

Vol.6 No. 1 Januari 2021

DOI : doi.org/10.21009/IJEEM.061.03

Teknik pengumpulan sampel untuk menentukan valuasi ekonomi objek daya tarik wisata dilakukan dengan teknik salah satu teknik non probability sampling yaitu dengan metode accidental sampling yaitu pengumpulan data sampel berdasarkan faktor spontanitas yaitu wisatawan yang secara tidak sengaja bertemu dengan peneliti. Wisatawan akan dijadikan sampel adalah wisatawan yang sedang berkunjung ke Pulau Harapan. Pada penelitian ini, jumlah sampel adalah sebanyak 36 wisatawan.

Nilai WTP akan diajukan kepada wisatawan melalui rentang nilai. Rentang Nilai yang dimaksud adalah Rp.50.000-Rp.100.000, Rp.100.000-Rp.150.000, Rp.150.000Rp.200.00, Rp.200.000-Rp.250.000. Kemudian dari rentang tersebut akan dihitung rataratanya dan akan diketahui nilai total WTP dari batas atas masing-masing rentang. Setelah dihitung rata-rata dari WTP, kemudian akan dicari nilai Break Even Point (BEP) untuk destinasi wisata Pulau Harapan. Nilai BEP akan berguna untuk mencari nilai optimum yang disesuaikan denga jumlah wisatawan yang optimum sehingga akan mendatangkan keuntungan (profit) dari jumlah wisatawan optimum. Proses mendapatkan data nilai WTP responden, dilakukan tahap-tahap sebagai berikut:

1. Membuat Pasar Hipotetik

Pasar hipotetik dibentuk atas dasar kerusakan lingkungan akibat eksploitasi sumber daya alam di TNKpS. Selain itu, aktivitas wisatawan yang berkunjung ke TNKpS turut membuat kualitas lingkungan di TNKpS menurun. Hal tersebut dapat diatasi dengan menggunakan salah satu instrumen ekonomi yaitu pembayaran jasa lingkungan yang di bayar oleh wisatawan sebagai kompensasi aktivitas wisatawan.

2. Mendapatkan Penawaran Besarnya WTP

Jika alat survei telah dibuat, maka survei dilakukan dengan kuisioner.

3. Memperkirakan Nilai WTP dan ATP

WTPi dapat didapatkan dengan cara melakukan nilai rata-rata dari penjumlahan keseluruhan nilai WTP dibagi dengan jumlah responden. Dugaan rataan WTP dibagi dengan rumus sebagai berikut: 


\section{$\mathrm{EWTP}=\sum^{\mathrm{n}} \mathrm{WiPfi}$}

Keterangan:

EWTP $=$ Dugaan rataan WTP

$\mathrm{Wi}=$ Nilai WTP ke-i

Pfi $=$ Frekuensi Relatif

$\mathrm{n}=$ Jumlah Responden

$\mathrm{i}=$ Responden ke-i yang bersedia melakukan pembayaran

$\mathrm{ATP}=($ Pendapatan/bulan $) \times(\%$ alokasi berwisata/bulan $)$

Frekuensi berlibur/bulan

Nilai rata-rata WTP yang didapat kemudian akan ditambahkan dengan harga paket destinasi wisata. Nilai tersebut akan menjadi Selling Price/Unit. Nilai Total Fixed Cost dan Variable Cost/Unit didapat dari nilai anggaran Balai Taman Nasional Kepulauan Seribu (BTNKpS) yang ditujukan untuk biaya operasi dan pemeliharaa Pulau Harapan.

4. Memperkirakan Nilai Break Even Point (BEP)

$\mathrm{BEP}=($ Total Fixed Cost + Target Profit $)$

(Selling Price/Unit-Variabel Cost/Unit)

\section{HASIL DAN PEMBAHASAN}

Riset ini dilakukan untuk mengkaji daya dukung dan valuasi ekonomi destinasi wisata di destinasi wisata Pulau Harapan. Destinasi wisata Pulau Harapan memiliki empat objek wisata yaitu Pulau Kayu Angin Melintang, Pulau Perak, Pulau Gosong, dan Pulau Putri (Balai Taman Nasional Kepulauan Seribu, 2019). Penamaan destinasi 
wisata Pulau Harapan sendiri didasari karena Pulau Harapan adalah salah satu pulau yang terletak di Kepulauan Seribu yang memiliki luas 6,70 ha. Meskipun begitu, pulau ini ditujukan sebagai wilayah pemukiman bagi penduduk Kepulauan Seribu.

Objek daya tarik yang terdapat di sekitar Pulau Harapan adalah Pulau Gosong, Pulau Perak, Pulau Putri, dan Pulau Kayu Angin Melintang. Wisatawan yang berkunjung ke Pulau Harapan hanya datang untuk menginap dan bersinggah. Kegiatan wisata yang dapat dilakukan sekitar wilayah ODTW adalah snorkeling, wisata pantai, diving, dan memancing. Aktivitas wisata yang sering digunakan oleh wisatawan adalah kegiatan snorkeling dan wisata pantai. Perlengkapan snorkeling dan wisata lainya disediakan oleh operator wisata.

Pulau yang terletak di sekita Pulau Harapan seperti Pulau Kayu Angin Melintang memiliki keunikan tersendiri. Salah satu keunikannya adalah Pulau tersebut memiliki pasir yang putih dan air laut yang jernih. Pulau Gosong memiliki pemandangan laut lepas dan tidak memiliki vegetasi di pulau tersebut sehingga sering dijaidkan sebagai lokasi untuk berfoto. Pulau Putri sudah dijadikan sebagai pulau wisata dan kepemilikannya sudah dialihkan ke pihak swasta, akan tetapi pengunjung Pulau Harapan dapat berkunjung ke pulau ini dengan membayar retribusi biaya masuk. Keunikan Pulau Perak cenderung sama dengan objek daya tarik lainnya, akan tetapi pulau ini memiliki pantai yang lebih luas jika dibandingkan dengan Pulau Kayu Angin Melintang.

\subsection{Daya Dukung Kawasan (DDK)}

Potensi ekologis wisatawan untuk keempat objek daya tarik tersebut adalah 1 orang dengan unit area $50 \mathrm{~m}^{2}$. Hal tersebut berarti setiap satu orang dalam $50 \mathrm{~m}^{2}$. Waktu yang dibutuhkan untuk pengunjung untuk kegiatan bermain di Pulau adalah satu jam. Pengunjung tidak membutuhkan waktu yang lama untuk bermain di pulau karena tidak banyak variasi kegiatan yang dapat dilakukan di pulau. Pengelola pulau membuka 


\section{IJEEM: Indonesian Journal of Environmental Education and Management \\ e-ISSN: 2549-5798 \\ Vol.6 No. 1 Januari 2021 \\ DOI : doi.org/10.21009/IJEEM.061.03}

waktu kunjungan pada sore hari yaitu pukul 15.00-17.00. Waktu yang disediakan operator wisata adalah selama dua jam dalam sehari. Jumlah kunjungan maksimum di dapat dari kapasitas maksimum kapal yang bersandar di pulau. Jumlah maksimum kapal yang dapat bersandar adalah 50 kapal dengan jumlah penumpang setiap kapal yaitu 30 penumpang.

Berdasarkan hasil analisis data, Pulau Gosong memiliki daya dukung lingkungan sebesar 160 orang/hari dan memiliki daya dukung pantai sebesar 160 orang/hari. Pulau Gosong menjadi yang paling kecil daya dukungnya karena luas pulau tersebut hanya $4.400 \mathrm{~m}^{2}$. Wisatawan menghabiskan waktu di Pulau Gosong sebanyak satu jam. Pulau Kayu Angin Melintang yang seluas 7,700 $\mathrm{m}^{2}$ dapat menampung wisatawan secara optimal sejumlah 308 orang/hari untuk satu pulau dan sebanyak 33 orang/hari untuk wilayah pantai. Pada kondisi terkini, Pulau Kayu Angin Melintang dapat didatangi oleh 1500 pengunjung pada satu waktu tertentu. Kondisi ini tentu melebihi daya dukung lingkungan dari Pulau Kayu Angin Melintang.

Tabel 2. Hasil Perhitungan Daya Dukung Kawasan di Destinasi Wisata Pulau Harapan

\begin{tabular}{|c|c|c|c|c|c|}
\hline \multirow[b]{2}{*}{$\begin{array}{l}\text { Nama } \\
\text { Pulau }\end{array}$} & \multicolumn{2}{|c|}{ Daya Dukung Pulau } & \multicolumn{2}{|c|}{ Daya Dukung Pantai } & \multirow[b]{2}{*}{$\begin{array}{c}\text { Jumlah } \\
\text { Kunjungan / } \\
\text { hari }\end{array}$} \\
\hline & $\begin{array}{c}\text { Luas } \\
\text { Pulau } \\
\left(\mathbf{m}^{2}\right)\end{array}$ & $\begin{array}{l}\text { Daya } \\
\text { Dukung } \\
\text { Pulau } \\
\text { (Orang/ } \\
\text { Hari) }\end{array}$ & $\begin{array}{c}\text { Luas } \\
\text { Pantai } \\
\left(\mathbf{m}^{2}\right)\end{array}$ & $\begin{array}{c}\text { Daya } \\
\text { Dukung } \\
\text { Pantai } \\
\text { (Orang/Hari) }\end{array}$ & \\
\hline $\begin{array}{l}\text { Kayu } \\
\text { Angin } \\
\text { Melintang }\end{array}$ & 7,700 & 308 & 820 & 33 & 1500 \\
\hline Perak & 30,600 & 1224 & 2,536 & 101 & 1500 \\
\hline Gosong & 67,000 & 160 & 1,242 & 160 & 200 \\
\hline Putri & 4,000 & 2680 & 4,000 & 50 & 1500 \\
\hline Jumlah To & & 4.372 & Jumlah & 344 & \\
\hline
\end{tabular}


IJEEM: Indonesian Journal of Environmental Education and Management

e-ISSN: 2549-5798

Vol.6 No. 1 Januari 2021

DOI : doi.org/10.21009/IJEEM.061.03

Pulau Perak yang memiliki luas $30.600 \mathrm{~m}^{2}$ mempunyai daya dukung sebesar 1.224 orang/hari untuk satu pulau dan sebanyak 101 orang/hari untuk wilayah pantai. Pulau ini pada kondisi terkini dapat didatangi sebanyak 1500 pengunjung. Kunjungan wisatawan ke Pulau Perak dapat melebihi daya dukung optimum. Pulau Putri yang memiliki luas $67.000 \mathrm{~m}^{2}$ memiliki daya dukung sebanyak 2.680 orang/hari dan memiliki daya dukung pantai sebesar 50 orang/hari. Pada kondisi terkini, Pulau Putri dapat didatangi hingga 1500 wisatawan. Daya dukung di Pulau Putri termasuk tinggi dibandingkan dengan pulau lainnya karena memiliki luas pulau yang besar. Pulau Putri sudah ada perubahan bentang alam sehingga konsep yang ditawarkan adalah semi alami.

Kedatangan wisatawan dengan jumlah yang melebihi daya dukung dapat memberikan berbagai dampak kepada objek wisata tersebut. Dampak yang diakibatkan dapat berupa kenyaman dan pengalaman pengunjung (tourism experience) dan berupa perubahan kondisi fisik dari objek daya tarik tersebut. Dampak tersebut dapat diminimalisisr dengan melakukan pembatasan wisatawan untuk menjaga keindahan objek wisata. Kehadiran wisatawan dapat menjadi prioritas dibandingkan jumlah wisatawan (Cooper et al, 1993). Kehadiran wisatawan dapat diartikan sebagai lama tinggal, lama berkunjung, karakteristik wisatawan, dan konsentrasi wisatawan pada lokasi geografis tertentu. Kunjungan wisatawan dengan jumlah yang melebihi daya dukung dapat membuat wisatawan tidak nyaman akibat terbatasnya ruang gerak. Aktivitas wisatawan untuk dapat menikmati keindahan jadi terganggu. Hal tersebut terbukti dari penilaian kriteria ODTW, pada unsur variasi kegiatan serta keindahan dan kenyamanan memiliki nilai yang rendah.

Kedatangan wisatawan dengan jumlah yang melebihi daya dukung dapat berpotensi mengurangi keindahan objek wisata karena wisatawan menghasilkan sampah yang mengurangi keindahan pemandangan. Mai (2018) mengatakan bahwa objek daya tarik wisata memiliki batas penggunaan sumber daya alam, yang jika penggunaannya 
IJEEM: Indonesian Journal of Environmental Education and Management

e-ISSN: 2549-5798

Vol.6 No. 1 Januari 2021

DOI : doi.org/10.21009/IJEEM.061.03

melampau batas maka akan menurunkan kualitas objek daya tarik tersebut. Dampak dari wisata yang melebihi daya dukung adalah menurunnya kualitas produk wisata. Mujiyani et al (2016) mengatakan bahwa terjadi kerusakan terumbu karang di Taman Nasional Kepulauan Seribu (TNKpS) akibat kegiatan wisata. Berdasarkan observasi di lapangan, pasir di pulau berubah warna menjadi hitam karena terinjak oleh wisatawan. Jika sebuah tempat wisata terus didatangi oleh wisatawan dengan jumlah yang melebihi daya dukung, kerusakan lingkungan akan lebih cepat terjadi yang berakibat pada menurunnya minat wisatawan untuk datang ke lokasi tersebut (Lee, 2012). Oleh karena itu, pulau yang kunjungan wisatawannya melebihi daya dukung optimum memerlukan pengelolaan yang berkelanjutan agar objek daya tarik dapat dikembangkan. Kategori tersebut dapat berubah sesuai dengan pengelolaan yang diberikan kepada objek daya tarik. Intervensi diperlukan untuk meningkatkan faktor kenyamanan dan keindahan.

\subsection{Nilai Ekonomi}

Berdasarkan hasil pengumpulan data di lapangan, nilai WTP pengunjung terhadap wisata di Pulau Harapan adalah Rp.50.000-Rp.100.000 yaitu sejumlah $52,768 \%$ pengunjung yang memilih rentang tersebut. Nilai tersebut adalah rentang pilihan yang paling rendah untuk diberikan kepada pengunjung. Nilai ATP pengunjung dihitung dari alokasi dana yang diberikan pengunjung untuk datang ke Pulau Harapan. Alokasi dana yang diberikan pengunjung untuk berlibur ke Pulau Harapan adalah sebesar Rp.200.000-Rp.500.000 yaitu sebanyak $33 \%$ pengunjung yang memilih rentang tersebut.

Nilai rata-rata WTP yang didapat adalah Rp.142.857. Nilai WTP tersebut lebih rendah jika dibandingkan dengan penelitian Meyliana (2015), yang mengatakan bahwa nilai WTP pengunjung destinasi wisata Pulau Harapan adalah Rp.500.000Rp.1.000.000. Penurunan nilai tersebut disebabkan karena terjadi penurunan manfaat yang diterima oleh konsumen dari jasa lingkungan (Meya, 2020). Penurunan manfaat 
IJEEM: Indonesian Journal of Environmental Education and Management

e-ISSN: 2549-5798

Vol.6 No. 1 Januari 2021

DOI : doi.org/10.21009/IJEEM.061.03

tersebut dapat terjadi karena penurunan kualitas lingkungan yang terdapat di destinasi wisata Pulau Harapan. Wisatawan akan bersedia membayar biaya tambahan sebesar nilai tersebut jika objek daya tarik wisata seperti Pulau Kayu Angin Melintang, Pulau Putri, Pulau Perak dan Pulau Gosong diterapkan pembatasan pengunjung. Biaya paket destinasi Pulau Harapan yang dikeluarkan oleh operator wisata adalah sebesar Rp.300.000 sehingga jika ditambahkan dengan nilai rata-rata WTP adalah Rp.442.857.

Pada kondisi terkini, Pulau Putri adalah pulau yang dijadikan sebagai resort. Pulau ini ditujukan untuk wisatawan yang datang dalam jumlah yang besar. Wisatawa yang berkunjung ke Pulau Putri melakukan aktivitas wisata yang memerlukan jumlah orang yang besar. Oleh karena itu, Pulau Putri didominasi oleh bangunan semi permanen.

Tabel 3. Nilai Rata-Rata Willingness To Pay

\begin{tabular}{|c|c|c|c|c|c|}
\hline \multirow{2}{*}{ No } & \multirow{2}{*}{ Range } & \multirow{2}{*}{$\begin{array}{c}\text { Batas Atas } \\
\begin{array}{c}\text { Willingness }) \\
(\mathbf{R p})\end{array}\end{array}$} & \multicolumn{2}{|c|}{ Jumlah } & \multirow{2}{*}{$\begin{array}{c}\begin{array}{c}\text { Rataan } \\
\text { WTP }\end{array} \\
\mathbf{W} * \mathbf{A}(\mathbf{R p}) \\
\end{array}$} \\
\hline & & & Frekuensi & Persentase & \\
\hline 1 & $\begin{array}{l}\text { Rp.50.000- } \\
\text { Rp.100.000 }\end{array}$ & 100.000 & 19 & 54.29 & 54.286 \\
\hline 2 & $\begin{array}{l}\text { Rp.100.000- } \\
\text { Rp.150.000 }\end{array}$ & 150.000 & 7 & 20 & 30.000 \\
\hline 3 & $\begin{array}{l}\text { Rp.150.000- } \\
\text { Rp.200.000 }\end{array}$ & 200.000 & 4 & 11.43 & 22.857 \\
\hline 4 & $\begin{array}{l}\text { Rp.200.000- } \\
\text { Rp.250.000 }\end{array}$ & 250.000 & 5 & 14.29 & 35.714 \\
\hline \multicolumn{2}{|c|}{ Jumlah Total } & & & & 142.857 \\
\hline
\end{tabular}

Hasil tersebut memperlihatkan bahwa nilai ATP lebih besar daripada nilai WTP. Menurut Setiadji (1993), nilai ATP lebih besar dari WTP memperlihatkan bahwa pengunjung yang datang ke destinasi wisata Pulau Harapan memiliki kemampuan membayar lebih besar daripada keinginan membayar lebih untuk objek daya tarik wisata bahari berkelanjutan. Hal ini terjadi jika wisatawan mempunyai penghasilan 
IJEEM: Indonesian Journal of Environmental Education and Management

e-ISSN: 2549-5798

Vol.6 No. 1 Januari 2021

DOI : doi.org/10.21009/IJEEM.061.03

yang relatif tinggi tetapi belum menjadikan Pulau Harapan sebagai destinasi wisata utama.

Tabel 4. Nilai Rata-Rata ATP Pengunjung Destinasi Wisata Pulau Harapan

\begin{tabular}{|l|l|l|l|l|}
\hline $\begin{array}{l}\text { Pendapatan/Tahun } \\
(\mathrm{Rp})\end{array}$ & $\begin{array}{l}\text { Anggaran } \\
\text { Berwisata }(\mathrm{Rp})\end{array}$ & $\begin{array}{l}\text { \%Alokasi } \\
\text { wisata }\end{array}$ & $\begin{array}{l}\text { Frekuensi } \\
\text { Liburan/bulan }\end{array}$ & ATP (Rp) \\
\hline 6.500 .000$. & 2.000 .000 & $30 \%$ & 3 & 650.000 \\
\hline
\end{tabular}

Nilai Break Even Point (BEP) wisatawan jika nilai jual ditambahkan dengan nilai WTP adalah 14.187 wisatawan. Hal tersebut menandakan bahwa untuk mencapai target keuntungan dari realisasi PNBP yaitu sebesar Rp.298.477.000 harus mendatangkan sejumlah 14.187 wisatawan setiap tahun. Nilai Total Fixed Cost didapat dari penjumlahan anggaran Balai TNKpS yang diketahui dari realisasi Penyerapan DIPA 2019. Nilai Total Fixed Cost adalah nilai pemeliharaan Pulau Harapan yang bersifat tetap, sedangkan nilai Variable Cost didapat dari nilai pemeliharaan yang nilainya bersifat fluktuatif tergantung dari jumlah penjualan. Target keuntungan didapat dari target Penerimaan Negara Bukan Pajak (PNBP) yang diterima dari wisatawan. Jika nilai BEP disesuaikan dengan daya dukung optimum, yaitu sebanyak 4.337 wisatawan, akan menghasilkan nilai jual sebesar Rp.727.500 untuk setiap paket. Nilai tersebut diatas nilai kemampuan wisatawan atau ATP yaitu sebesar Rp.650.000.

Tabel 5. Nilai BEP Wisatawan Disesuakan dengan Daya Dukung

\begin{tabular}{|c|c|c|c|}
\hline No & Variabel & Eksisting+Paket (Rp) & Rencana (Rp) \\
\hline 1 & Total Fixed Cost & 1.748 .234 .000 & 1.748 .234 .000 \\
\hline 2 & $\begin{array}{l}\text { Selling } \\
\text { Price/Unit } \\
\end{array}$ & 442.857 & 727.500 \\
\hline 3 & $\begin{array}{l}\text { Variabel } \\
\text { Cost/Unit }\end{array}$ & 317.522 & 317.522 \\
\hline 4 & Target Profit & 298.477 .000 & 298.477 .000 \\
\hline & $\begin{array}{l}\text { Jumlah } \\
\text { (wan) }\end{array}$ & 14.187 & 4337 \\
\hline
\end{tabular}


IJEEM: Indonesian Journal of Environmental Education and Management

e-ISSN: 2549-5798

Vol.6 No. 1 Januari 2021

DOI : doi.org/10.21009/IJEEM.061.03

Nilai WTP pengunjung yang datang ke destinasi wisata Pulau Harapan tidak terlalu tinggi jika dibandingkan dengan nilai WTP di destinasi pariwisata bahari lainnya. Pada saat pengumpulan data, beberapa pengunjung menilai bahwa destinasi wisata Pulau Harapan tidak mempunyai suatu hal iconic atau langka untuk dilihat. Common \& Stagl (2015) mengatakan bahwa wisatawan akan rele membayar berapa saja untuk melihat dan menikmati hal yang belum dilihat sebelumnya. Selain itu, wisatawan yang berkunjung ke destinasi wisata Pulau Harapan pada umumya adalah wisatawan yang berasal dari DKI Jakarta dan sekitarnya. Anggaran untuk berlibur digunakan untuk melakukan liburan ke destinasi wisata yang lebih jauh seperti P.Komodo, Bali, dan Bunaken. Hal tersebut membuktikan bahwa destinasi wisata Pulau Harapan perlu meningkatkan popularitasnya dan menentukan sebuah icon destinasi agar wisatawan mau membayar lebih.

\subsection{Penentuan Nilai Ekonomi Objek Daya Tarik Wisata Berkelanjutan}

Lee (2019) mengatakan bahwa harga dari barang dan jasa lingkungan ditentukan oleh penawaran (supply) dan permintaan (demand). Permintaan adalah sebuah konsep yang merefleksikan keuntungan (profit), dan penawaran adalah sebuah konsep yang merefleksikan modal (cost). Harga dari sebuah barang dan jasa lingkungan ditentukan oleh ketersediaan modal dan tingkat permintaan dari barang dan jasa lingkungan. Penerapan konsep ekowisata di destinasi wisata Pulau Harapan dapat menjaga objek daya tarik wisata di destinasi wisata Pulau Harapan dapat terkelola secara lestari dan berkelanjutan. Pengertian Ekowisata menurut Mcormik (1994) adalah kegiatan perjalanan menuju suatu daerah alami yang bertujuan untuk mengenal budaya dan sejarah alam dari daerah tersebut tanpa melakukan perubahan terhadap integritas dari ekosistem di daerah tersebut, dengan mendatangkan keuntungan ekonomi yang membuat kegiatan konservasi menjadi sebuah penghasilan bagi penduduk lokal. Weaver (2011) membedakan pariwisata menjadi dua bentuk yaitu pariwisata massal (mass tourism) dan pariwisata alternatif (alternative tourism). Kiper (2011) 


\section{IJEEM: Indonesian Journal of Environmental Education and Management \\ e-ISSN: 2549-5798 \\ Vol. 6 No. 1 Januari 2021 \\ DOI : doi.org/10.21009/IJEEM.061.03}

mendefinisikan pariwisata massal sebagai bentuk pariwisata tradisional dan bertujuan untuk mendatangkan pendapatan yang sebanyak banyaknya. Perbedaan antara pariwisata massal dan alternatif terletak pada jumlah dan perilaku dari wisatawan Berdasarkan hasil penelitian daya dukung wisata dan nilai ekonomi, pada tabel 4.2 terlihat bahwa jika wisatawan yang datang melampaui batas dan destinasi wisata Pulau Harapan menggunakan prinsip wisata massal, maka kualitas lingkungan di destinasi wisata Pulau Harapan dapat menurun dan mengakibatkan menurunnya permintaan wisatawan untuk datang ke destinasi wisata Pulau Harapan.

Tabel 6. Penyesuaian Harga dengan Daya Dukung Kawasan

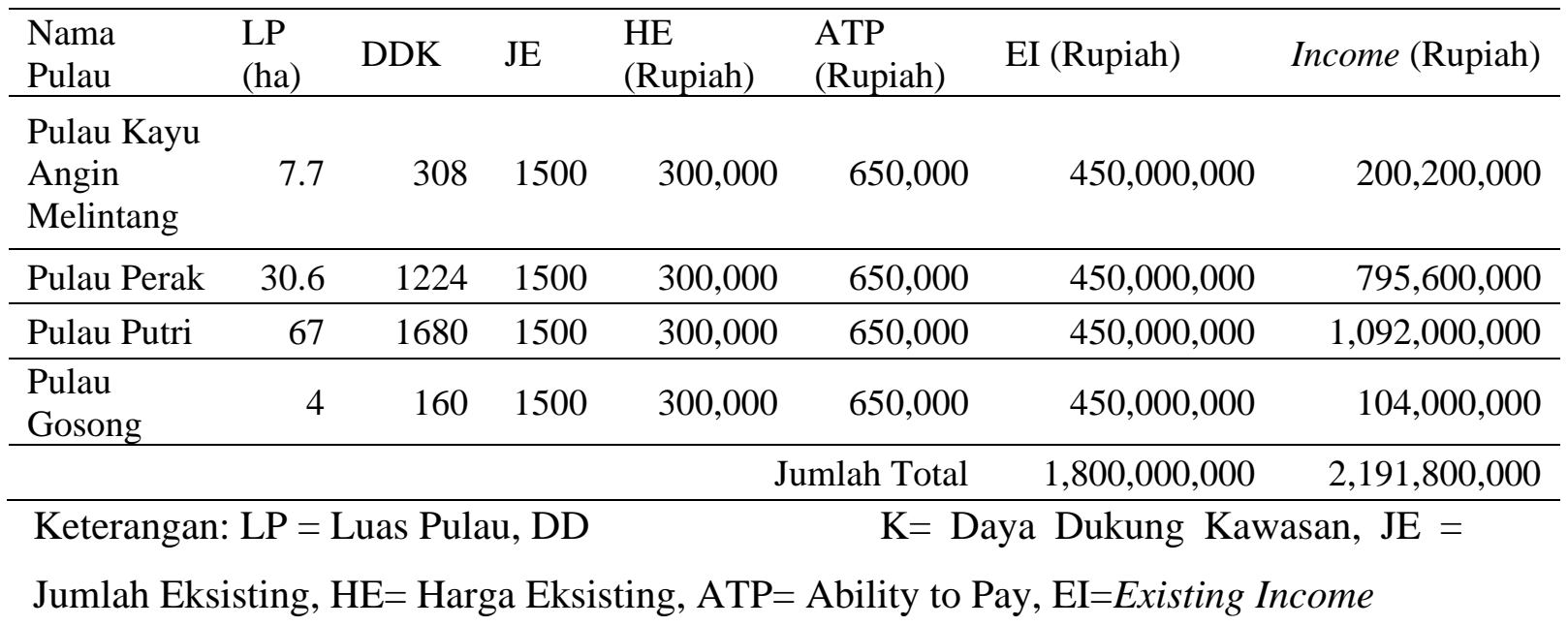

Jumlah wisatawan yang mendatangi destinasi wisata Pulau Harapan adalah 1.500 wisatawan dengan harga Rp.300.000. Permintaan wisatawan dapat meningkat jika kondisi destinasi wisata Pulau Harapan sesuai dengan yang dibutuhkan oleh wisatawan. Atraksi, pengalaman, keindahan objek wisata destinasi wisata Pulau Harapan dapat ditingkatkan kualitasnya agar dapat meningkatkan minat dan permintaan wisatawan. Intervensi yang dapat dilakukan adalah dengan melakukan pembatasan pengunjung dan meningkatkan harga masuk destinasi wisata Pulau Harapan sesuai dengan kemampuan wisatawan untuk membayar atau ability to pay (ATP). Pemasukan 


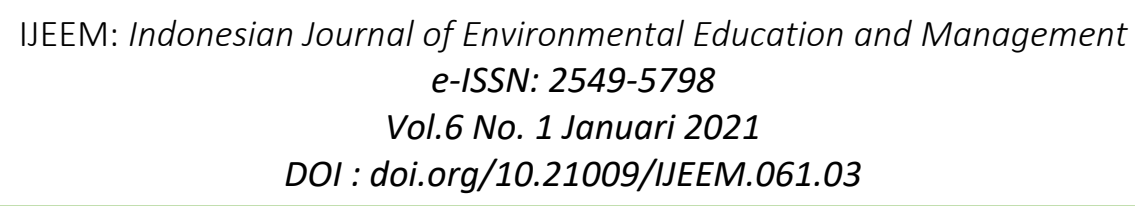

(Income) yang dapat diterima oleh pengelola destinasi wisata Pulau Harapan adalah Rp.2.191.800.000. Pemasukan yang diterima oleh pengelola jika menggunakan wisata massal adalah Rp.1.800.000.000. Permintaan wisatawan dapat ditingkatkan dengan menjaga dan meningkatkan kualitas prorduk wisata di destinasi wisata Pulau Harapan.

\section{KESIMPULAN}

Jumlah daya dukung destinasi wisata Pulau Harapan adalah sebanyak 4.372 wisatawan dan memiliki nilai ekonomi sebesar Rp.442.857. Nilai kemampuan untuk membayar atau atau Ability To Pay (ATP) wisatawan Pulau Harapan adalah Rp.650.000. Destinasi wisata Pulau Harapan dapat menerapkan pembatasan pengunjung untuk meningkatkan kualitas keindahan objek daya tarik wisatanya.

\section{REFERENSI}

Common, M., Stagl, S., (2005). Ecological Economics: An Introduction. United Kingdom: Cambridge.

Kenell, J. (2015). Carrying Capacity, Tourism. Encyclopedia of tourism. Springer Interntional Publishing.

Kiper, T.(2013). The Role of Ecotourisme in Sustainable Development. Turkey: Namik Kemal University.

Koutulas, D.(2015). Understanding the Tourism Product. Greece: University of Aegean

Kusrini, D., Wardianto., Y., Yulianda, F.(2013). Aquatic Ecosystem Development For Ecotourism Destination. Ecotourism and Unstable Tourism Development In Indonesia: Potential, Lessons, and Best Practices: Ministry Of Tourism and Economic Creative.

McCromik.K. (1994). Can Ecotourism Save The Rainforest? Rainforest Action Network 


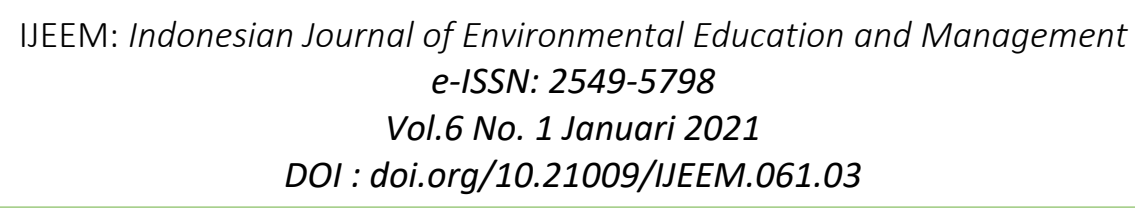

Miller, T. G, Spoolman, E.S. (2010). Environmental Science. Amerika Serikat: Brooks/Cole.

Mujiyani, H., Rachmawati.D., Soetopo.L., Bayu.T., Cahyadi.,A. (2002). Pengelolaan Pulau Pulau Kecil: Partisipasi Masyarakat di Kepulauan Seribu. Jakarta: LIPI.

Rahakabauw, S., Teniwut, M., Renjaan, M.,Hungan, M. (2017). Increase Economic Valuation of Marine Ecotourism Spot In Small Island. MSFT2012.

Rangkuti, F. (2016). Teknik Membedah Kasus Bisnis: Analisis SWOT Cara Perhitungan Bobot, Rating, dan OCAI. Jakarta: PT Gramedia Pustaka

Razak, N. (2017). Ekowisata: Manajemen Kawasan Konservasi. Surabaya:Fajar Harapan

Richardson, L., Loomis, J., (2008): The Total Economic Value Of Threatened, Endengared and Rare Species: An Updated Meta-Analysis. Ecological Economics 1535-1548

Salafsky, N., Salzer, D., Statersfield, A., Hilton-taylor, C., Neugarten, R., Butchart, S., Collen, B., Cox, N., Master, L., O’Connor, S., Wilkie, D. (2007). A Standard Lexicon for Biodiversity Conservation: Unified Classifications of Threats and Actions. Conervation Biology Vol.22 No.4, 897-911. US

Salim, E. (1986). Pembangunan Berwawasan Lingkungan. Jakarta: LP3ES

Setyorini, H., Effendi, M., Santoso, I.(2016). Analisis Strategi Pemasraan Menggunakan Matriks SWOT dan QSPM (Studi Kasus: Restoran WS Malang. Inustria: Jurnal Teknologi dan Manajemen Industri. Vol 5 Nomor 1.

Schumann, P., Skeete, R., Weite, R., Lorde, T., Skeete, P., Oxenford, H., Gill, G, Moore, W., Spencer, F. (2018). Visitors' willingness to pay marine conservation fees in Barbados. Tourism Management.

Schutgens, M., Hanson, J., Barau, N. (2018). Visitors' willingness to pay for snow leopard Panthera uncia conservation in the Annapurna Conservation Area, Nepal. Nepal: Fauna Flora International.

Soemarwoto, O. (1983). Ekologi, Lingkungan Hidup dan Pembangunan. Jakarta: Imagraph 


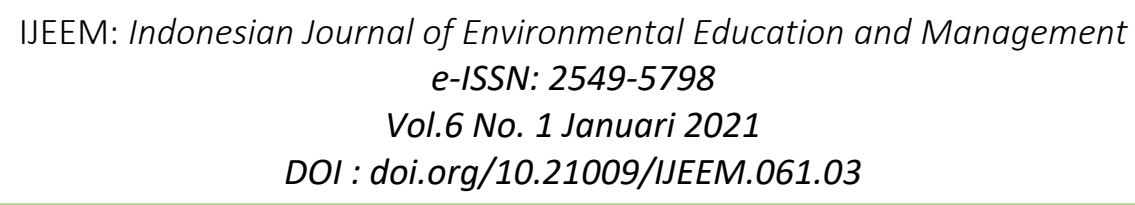

Suparmoko, M. (2014). Valuasi Ekonomi dan Sumber Daya Alam \& Lingkungan. Jakarta: BPFE

Tuwo, A. (2011). Pengelolaan Ekowisata Pesisir dan Laut: Pendekatan Ekologi, Sosial-Ekonomi, Kelembagaan, dan Sarana Wilayah. Surabaya: Brilian Internasional

UNEP \& UNWTO. (2012). Making Tourism More Sustainable. A Guide For Policy Makers. New York: United Nations Envronment Programme and World Tourism Organization.

Van Hove, N (2011). The Economics Of Tourism Destination: Second Edition. New York: Rutledge

Vianna, G., Meekan, G., Rogers, A., Kragt, M., Alin, J., Zimmerhackel, J. (2018). Shark-diving tourism as a financing mechanism for shark conservation strategies in Malaysia . Journal of Marine Policy 94 220-226

Watkin, J. (2002). The Evolution of Ecotourism in East Africa: From an Idea to an Industry. IIED Wildlife and Development Series No.15

Yusnita, I. (2014). Kajian Potensi Dampak Wisata Bahari Terhadap Terumbu Karang Di Keluarahan Pulau Panggang, Kepulauan Seribu. Bogor: IPB 